\title{
Can Elastic Band Resistance Training Programs Mitigate Holiday Weight Gain and Improve Hand-Grip Strength in Older Women?
}

\author{
¿Pueden los Programas de Entrenamiento de Resistencia con Banda Elástica Mitigar el Aumento de \\ Peso Durante las Vacaciones y Mejorar la Fuerza de Agarre de las Manos en Mujeres Mayores?
}

\author{
Rubén López ${ }^{1}$; Paula Cisternas-Vallejos²; Yesenia Devaud ${ }^{3}$; Rodrigo Muñoz-Cofré4 \\ Alejandro Gómez-Bruton ${ }^{5}$ \& Pablo A. Lizana ${ }^{2}$
}

LÓPEZ, R.; CISTERnAS-VAlleJOS, P.; DEVAUD, Y.; MUÑOZ-COFRE, R; GÓMEZ-BRUTON, A. \& LIZANA, P. A.. Can elastic band resistance training programs mitigate holiday weight gain and improve hand-grip strength in older women? Int. J. Morphol., 38(5):1173-1178, 2020.

SUMMARY: This study evaluated the effect of resistance exercise training (RET) on body composition and muscle strength in 16 older women during summer holidays (70.5 \pm 8.4 years old; Range 60-87). Exercise sessions were carried out for twelve weeks, two sessions per week, with 60 minutes of exercise per session. We measured body mass index (BMI), fat mass percentage (FM\%, by bioimpedance) and grip strength with a dynamometer before and after the intervention. The participants showed a significant increase in BMI ( $\mathrm{p}<0.05)$, FM\% ( $<<0.001)$, and a significant gain in grip strength $(\mathrm{p}<0.05)$. The RET program could be an important strategy for improving strength for older women, but we would suggest combining it with other interventions, such as aerobic exercises with gradually increasing intensity and nutrition interventions, in order to maintain a steady weight during holiday periods.

KEY WORDS: Older adults; Body composition; Exercise program; Resistance training; Hand Strength.

\section{INTRODUCTION}

Body composition (BC) undergoes significant changes in older adults $(\mathrm{OA})$, typically expressed in reduced muscle and bone mass, and increased fat mass (Buffa et al., 2011), which constitute an unfavorable factor for OAs, impacting overall health, functional independence and quality of life (Frisoli et al., 2011; Falsarella et al., 2015). Physical activity (PA) is proven to reduce the risk - or even prevent - developing chronic non-communicable diseases (NCDs), a leading cause of OA deaths (Warburton et al., 2006). The factors and causes associated with this could provide a framework for intervention strategies focused on active OA participation in training programs (Bouaziz et al., 2017). Accordingly, one intervention with observed improvements in muscle mass, muscle mass quality, and reduced muscle mass loss is resistance exercise training (RET) (Schulte \& Yarasheski, 2001; Yarasheski et al., 2003; Liao et al., 2018). Furthermore, RET has been used with weak older adults, increasing muscle mass. There is also evidence that RET improves physical functions, including strength, also improving performance in simple and complex tasks for older adults (Liu \& Latham, 2009).

While studies indicate that a BMI in the moderately obese range could be associated with a slight increase in the risk of OA mortality (Janssen \& Mark, 2007), this also indicates the fact that there are more OAs with NCDs, which generates multiple impacts on society, such as a high demand on health systems and significant expenditure on public resources (Prince et al., 2015). In Chile, the latest National Health Survey (ENS 2016-2017) (Ministerio de Salud, 2017) found that $94 \%$ of OAs over the age of 65 are sedentary with a prevalence of $76.8 \%$ of overweight or obesity, 73.3 $\%$ hypertension and $30.6 \%$ showing signs of mellitus diabetes. It therefore seems like OAs present several factors that increase cardiovascular risk, linked with higher rates of acute myocardial infarction and cerebrovascular events, resulting in $14.4 \%$ of OAs with some degree of dependency (Ministerio de Desarrollo Social, 2016).

\footnotetext{
${ }^{1}$ School of Kinesiology, Pontificia Universidad Católica de Valparaíso, Chile.

${ }^{2}$ Laboratory of Morphological Sciences, Instituto de Biología, Pontificia Universidad Católica de Valparaíso, Chile.

${ }^{3}$ Municipal Social Development Corporation. Ilustre Municipalidad de Lampa, Chile.

${ }^{4}$ Programa de Doctorado en Ciencias Morfológicas, Universidad de La Frontera, Chile.

${ }^{5}$ GENUD “Growth, Exercise, Nutrition and Development” Research Group, Faculty of Sport and Health Sciences, Universidad de Zaragoza, Zaragoza, Spain
} 
LÓPEZ, R.; CISTERNAS-VALLEJOS, P.; DEVAUD, Y.; MUÑOZ-COFRE, R; GÓMEZ-BRUTON, A. \& LIZANA, P. A.. Can elastic band resistance training programs mitigate holiday weight gain and improve hand-grip strength in older women? Int. J. Morphol., 38(5):1173-1178, 2020.

Additionally, studies have reported that the greatest annual weight gain occurs during short periods of time such as holiday weekends or vacations, known as "holiday weight gain" (Stevenson et al., 2013). This may be associated with increased caloric intake and low energy expenditure, causing an imbalance resulting in weight gain. In the United States, an average weight gain of $3.6 \mathrm{~kg}$ is reported during holidays (Yanovski et al., 2000; Payab et al., 2015). It has also been reported that the risk of weight gain is higher for obese people (Stevenson et al.). However, studies on OAs during vacation periods are scarce. A pilot study on OAs in Chile has shown that during the holidays there is a decrease in fat-free mass and an increase in fat mass (Lizana et al., 2016). This could be due to the fact that OAs are engaged in physical activity maintenance classes during the year that stop during the holiday periods. Therefore, the present study aims to evaluate whether an elastic band resistance training program directed to a group of OAs during summer vacation modifies changes in body composition and muscle strength.

\section{MATERIAL AND METHOD}

Participants. Our study is quasi-experimental of the pretest/post-test. The participants were recruited for the study by means of passing out flyers, word of mouth and announcements in OA social club meetings in Lampa, Santiago (coordinates: $33^{\circ} 19^{\prime} 27.84^{\prime \prime} \mathrm{S}, 70^{\circ} 45^{\prime} 33.12^{\prime \prime} \mathrm{W}$ ) with the support of the More Self-Sufficient Senior Citizens program of the community. The inclusion criteria were: Female sex, aged over 60 with the ability to participate in exercise sessions, signed informed consent of participation and physical independence as in Spirduso (1995) (older adults who perform all the basic and intermediate activities of daily living), and who complied with the interventions and both evaluations. The exclusion criteria were: Locomotor injuries that impair performance of exercises, neuromuscular problems, uncontrolled hypertension, acute myocardial infarction or stroke in the last year. The first test visit (E1) was in midJanuary, while the second test visit occurred after the holiday season at the end of March (E2), 2016 (the summer period in Chile is from December to March). The average interval between evaluations was $80.33 \pm 8.68$ days.

Body composition and muscle strength. Mass was determined with a Seca 813 scale (Seca, Hamburg, Germany) and height with a Seca 217 stadiometer (Seca, Hamburg, Germany). BMI (mass in kilograms/height in squared meters) was calculated and categorized according to Chilean norms (MINSAL, 2015). A bioelectrical impedance device was used for the evaluation of body composition: FM (kg) and FM\% (TANITA BC 420 SMA, Tanita, Toyko, Japan). All evaluations were carried out in the same OA social club meetings (community center), during morning, safeguarding the subjects' privacy and comfort. In addition, they were asked to urinate before the test, and to remove all metal objects, to refrain from intense exercise the previous day and to avoid consuming diuretics, alcohol or caffeine in the same period.

A hand-grip test was performed with a Jamar@ Hydraulic Hand Dynamometer (J. A. Preston Corporation, Clifton, NJ) with an accuracy of $0.1 \mathrm{~kg}$, using the dominant hand. The measurement was taken with the participant standing up, adjusting the handle until the participant's fingers were in a plane perpendicular to the scale (device clock), asking the participants to exert as much force as possible with their hand. Two measurements were taken and the best attempt was recorded.

Training sessions. Exercise sessions were carried twice per week (Tuesdays and Thursdays) during twelve weeks. Each exercise session lasted approximately 60 minutes. Sessions were directed and supervised by a physiotherapist (PT) and an occupational therapist (OT). The exercises consisted of a warm-up and joint mobility of the whole body; a fundamental exercise where muscle strength was mainly worked using corporal RET from the body, exercising the gluteus, quadriceps and hamstrings by means of semi-squats and medium resistance elastic bands (green; Theraband, Hygenic Co., Akron, $\mathrm{OH}, \mathrm{USA}$ ), exercising muscle chains bilaterally (biceps, triceps, trapezium, latissimus dorsi, abdominals and hip abductors). A progression sequence of the exercise followed, starting with 2 sets of 10 repetitions, with 20 seconds rest between each series, to conclude the intervention with 3 sets of 25 repetitions and 20 seconds rest between each set. Each session ended with a cool-down, which consisted of muscular elongations for each worked muscle group (2 series, maintaining 15 seconds for each elongation) and imaging, concentrating on the process of inhalation and exhalation.

Statistical Analysis. Descriptive statistics are presented as mean and standard deviation. Group comparisons for anthropometric measurements and body composition were performed using the T-test or Mann-Whitney U-test for paired samples according to the Shapiro-Wilk normality test. Analyses were done using the STATA 12.1 program. The alpha level accepted as significant for all statistical procedures was 0.05 .

Bioethical aspects. Our study was approved by the Bioethics Committee of the Pontificia Universidad Católica de Valparaíso, Chile. Before the evaluations, participants were gathered, and the research scope and objectives were explained to them in a presentation. Subsequently, participants signed informed consent forms to participate in the investigation. 


\section{RESULTS}

The sample consisted of 16 older women whose socio-demographic characteristics were: $70.5 \pm 8.40$ years of age. Participants showed a significant gain in body mass, BMI, FM and FM\% and hand-grip strength (all p<0.05; Table I).
Figures 1 to 3 show changes in BMI, FM\%, and handgrip for each participant. Nine participants $(56.25 \%)$ showed increased BMI (Fig. 1), fifteen (93.75 \%) showed a FM\% increase (Fig. 2), and fourteen participants (87.5\%) showed an increased in hand-grip strength (Fig. 3).

Table I. Intervention group, two session of exercise per week. Anthropometric measures and body composition changes of female older adults from Santiago, Chile $(n=16)$. Summer holidays (January-March) 2016.

\begin{tabular}{lclll}
\hline Variables & \multicolumn{1}{c}{ Before } & \multicolumn{1}{c}{ After } & Change & P-value $^{\mathrm{b}}$ \\
\hline Age (years) & $70.5 \pm 8.40$ & - & - & - \\
Height $(\mathrm{cm})$ & $152.2 \pm 5.88$ & - & - & - \\
Weight $(\mathrm{kg})$ & $71.23 \pm 12.26$ & $71.82 \pm 12.51$ & $0.59 \pm 0.98$ & 0.028 \\
Body Mass Index & $30.61 \pm 4.15$ & $30.88 \pm 4.33$ & $0.27 \pm 0.44$ & 0.027 \\
Fat Mass $(\mathrm{kg})^{\mathrm{a}}$ & $28.04 \pm 8.09$ & $30.00 \pm 8.15$ & $1.96 \pm 1.11$ & $<0.001$ \\
Fat Mass $(\%)^{\mathrm{a}}$ & $38.63 \pm 4.88$ & $41.11 \pm 4.59$ & $2.49 \pm 1.42$ & $<0.001$ \\
Hand-grip strength $(\mathrm{kg})$ & $23.75 \pm 5.94$ & $25.69 \pm 5.03$ & $1.94 \pm 2.79$ & 0.014 \\
\hline
\end{tabular}

Values presented as means \pm standard deviation. aAssessed by bio impedance (TANITA BC-420MA). bChanges in measured variables from pre-to post summer holiday season were tested using paired t test.

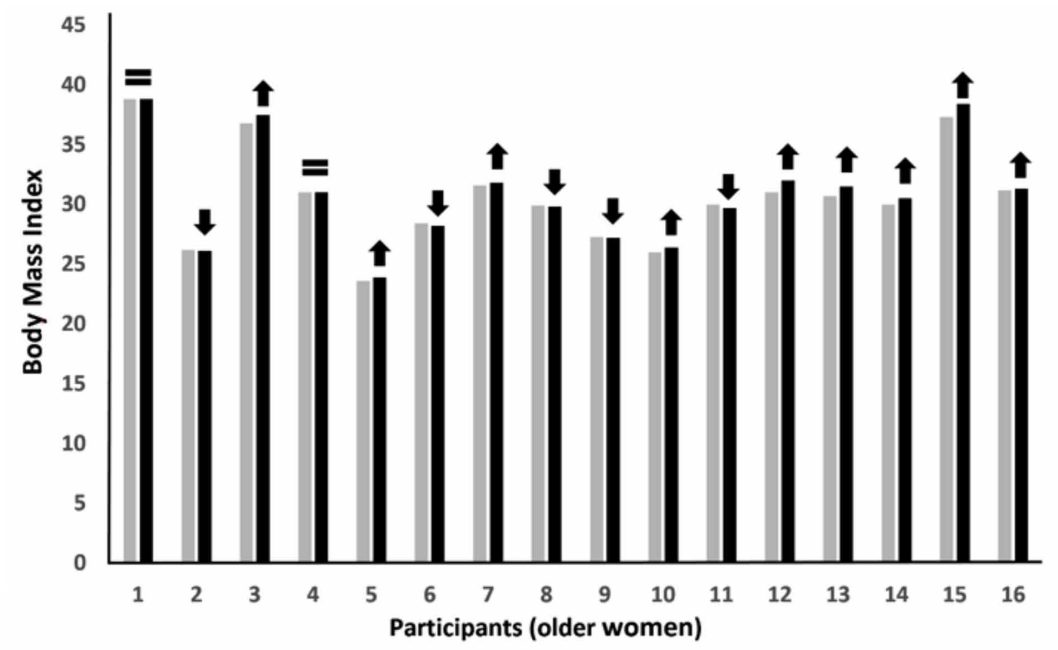

Fig. 1. Changes in body mass index during summer holiday (2016) in older women from Valparaíso, Chile. Gray bars indicate pre-holiday season and black bars indicate postholiday season. The black arrow indicates the change between pre and postholiday.

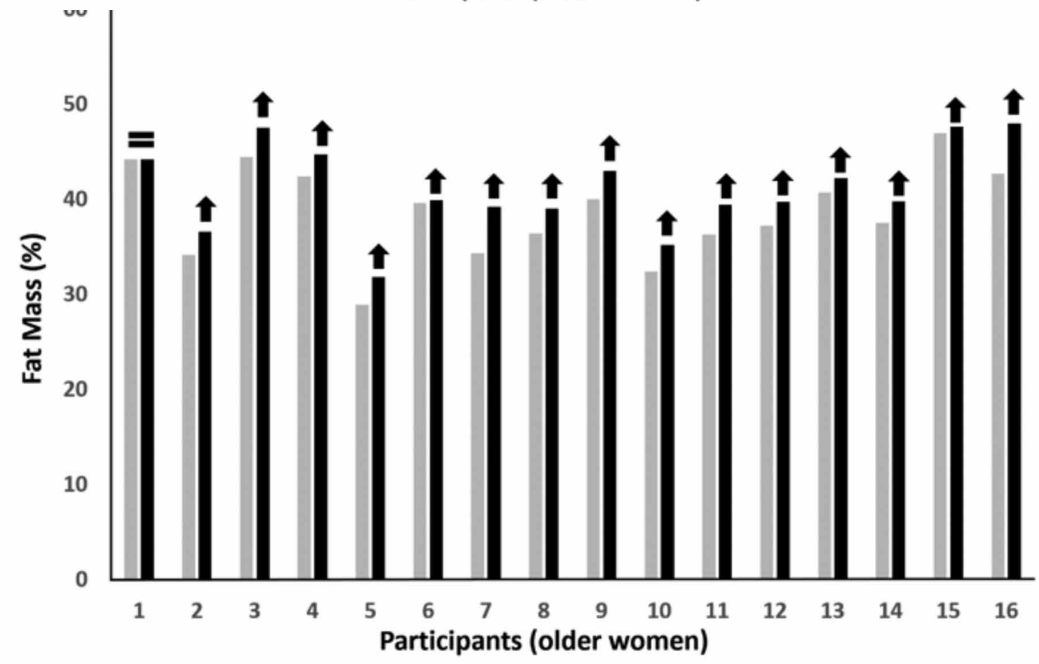

Fig. 2. Changes in fat mass percentage during summer holiday (2016) in older women from Valparaíso, Chile. Gray bars indicate pre-holiday season and black bars indicate postholiday season. The black arrow indicates the change between pre and postholiday. 


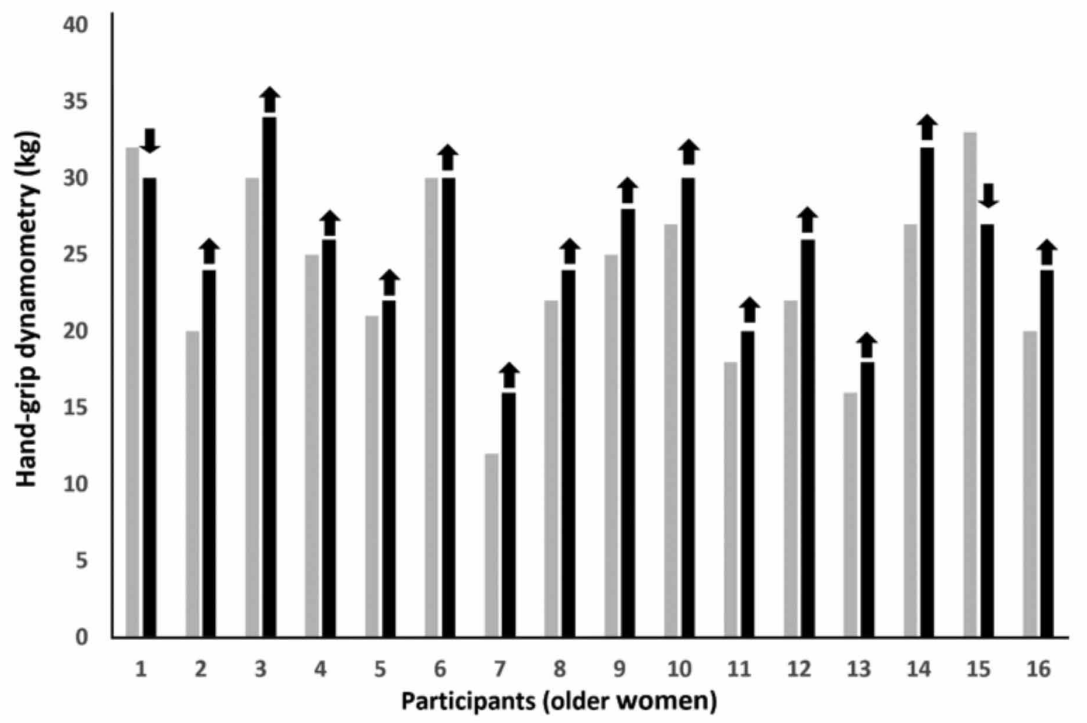

Fig. 3. Changes in hand-grip dynamometry $(\mathrm{kg})$ during summer holiday (2016) in older women from Valparaíso, Chile. Gray bars indicate pre-holiday season and black bars indicate postholiday season. The black arrow indicate change between pre and postholiday.

\section{DISCUSSION}

The present study has shown that OA increase FM and $\mathrm{FM} \%$ in the holiday period even after performing a resistance training during summer vacation. Nonetheless, the training improved hand-grip strength. Our results are comparable to those of Payab et al., on BC during holidays, where they describe a significant increase in BMI in adults aged 21 to 68 . Stevenson et al., also working with a wide age range (18 to 65), showed significant increases in body mass, BF \%, weight, FM\% and systolic blood pressure. Interestingly, the Stevenson et al. group consulted participants on their PA habits and those who reported 150 minutes of moderately intense exercise per week were classified as "exercisers" while those who reported less than 150 minutes per week were categorized as "non-exercisers". Despite the categorization made by the authors, PA was not a protective element against weight gain and $\mathrm{BF} \%$ increases. These findings coincide with our study, which demonstrated that a resistance exercise program was not protective against $\mathrm{BF} \%$ increases during the summer. The increase in $\mathrm{BF} \%$, may be due to the fact that daily caloric intake exceeded energy expenditure. Additionally, it has been reported that a higher BMI is associated with higher daily energy intake and intake per meal (Howarth et al., 2007), therefore, we suggest incorporating this variable in future studies. Another explanation for the $\mathrm{BF} \%$ increase may be the weekly training volume, as the ACSM recommendations state that exercise programs need to exceed 225 minutes per week in order to possibly induce clinically significant weight loss (Donnelly et al., 2009), while our participants only received 120 minutes per week. In this line, Huang et al. (2017) reported that progressive RET three times per week (instead of two times per week as performed in the present study) for 12 weeks caused significant reductions in $\mathrm{BF} \%$ for older women with sarcopenic obesity. Moreover, our sessions were mainly focused on resistance training. It is therefore possible that if more aerobic exercise had been included in the sessions different results would have been found with participants showing a maintenance or reduction in body fat as found in previous studies (Donnelly et al.; Friedenreich et al., 2011). However, it is worth noting that planned resistance exercise did have beneficial results for the intervention group. In this regard, it has been reported that resistance exercises for OAs have better results than endurance training in relation to increases in lean mass, muscle strength, and grip strength (Rogers et al., 2002; Strasser et al., 2009). In addition, a systematic review confirms the effectiveness of resistance exercise for healthy OAs on muscle strength and upper and lower limb morphology (Borde et al., 2015), with a recent study showing positive effects on muscle mass, muscle mass quality, and physical function in older women with sarcopenic obesity, using RET for 12 weeks (Liao et al.), which shows RET with older women has a significant impact on their quality of life. However, further studies are required on optimal doseresponses for healthy OAs with limited mobility and/or frailty (Borde et al.).

Our study presents several limitations. The first is that bioelectric impedance was used to estimate BC. Although this is not the gold standard for assessing BC, we followed all necessary protocols, such as hydration, physical activity, avoiding wearing jewelry, among others (see the methods 
section), to make the experiment reproducible. We also used validated and recommended equipment for epidemiological studies (Lloret Linares et al., 2011). Another limitation was the intake evaluation, which in this case could have constituted a relevant variable in order to explain $\mathrm{BC}$ changes. A third limitation is that, because our research focused on summer vacation effects, no follow-up measurements were made to observe changes in $\mathrm{BC}$ over time, an interesting aspect for future research. Another limitation was that a control group was not incorporated. Finally, all subjects were from a single area (Lampa, Región Metropolitana, Chile) and therefore, although representative to some extent, it is not conclusive for the rest of the Chilean population. However, in accordance with Lizana et al., our study agrees that summer vacation is a critical period which must be considered in OA public health programs. In conclusion, the present study reports the positive effects of 12 weeks of RET on grip strength in older women. However, this was not enough to stabilize or reduce FM\% during the summer vacation period. The RET program may be a successful strategy in increasing strength for older women, but other variables, such as exercise intensity and consumption, must also be considered.

\section{ACKNOWLEDGEMENTS}

The authors are grateful to the Direction and Vicerectory of Research and Advanced Studies, Biology Institute, Faculty of Sciences at the Pontificia Universidad Católica de Valparaíso, Chile, for their constant support.

LÓPEZ, R.; CISTERNAS-VALLEJOS, P.; DEVAUD, Y.; MUÑOZ-COFRE, R; GÓMEZ-BRUTON, A. \& LIZANA, P. A. ¿Pueden los programas de entrenamiento de resistencia con banda elástica mitigar el aumento de peso durante las vacaciones y mejorar la fuerza de agarre de las manos en mujeres mayores? Int. J. Morphol., 38(5):1173-1178, 2020.

RESUMEN: Este estudio evaluó el efecto del entrenamiento con ejercicios de resistencia (EER) sobre la composición corporal y la fuerza muscular en 16 mujeres adultas mayores durante las vacaciones de verano (70,5 $\pm 8,4$ años; Rango 60-87). Las sesiones de ejercicio se llevaron a cabo durante doce semanas, dos veces por semana, con 60 minutos de ejercicio por sesión. Se evaluó el índice de masa corporal (IMC), el porcentaje de masa grasa ( $\%$ MG, por bioimpedancia) y la fuerza de presión con un dinamómetro manual antes y después de la intervención. Las participantes mostraron un aumento significativo en el IMC ( $p<0,05)$, \% de MG (p $<0,001)$ y un incremento significativo en la fuerza prensil $(\mathrm{p}<0,05)$. El programa de EER podría ser una estrategia importante para mejorar la fuerza de mujeres adultas mayores durante el periodo estival. El EER se sugiere combinarlo con otras variables, como ejercicios aeróbicos con intensidad gradualmente creciente y una intervención nutricional, para mantener un peso constante durante los períodos de vacaciones.

PALABRAS CLAVE: Adultos mayores; Composición corporal; Programa de ejercicio; Entrenamiento de resistencia; Fuerza prensil.

\section{REFERENCES}

Borde, R.; Hortobágyi, T. \& Granacher, U. Dose-response relationships of resistance training in healthy old adults: a systematic review and metaanalysis. Sports Med., 45(12):1693-720, 2015.

Bouaziz, W.; Vogel, T.; Schmitt, E.; Kaltenbach, G.: Geny, B. \& Lang, P. $O$. Health benefits of aerobic training programs in adults aged 70 and over: a systematic review. Arch. Gerontol. Geriatr., 69:110-27, 2017.

Buffa, R.; Floris, G. U.; Putzu, P. F. \& Marini, E. Body composition variations in ageing. Coll. Antropol., 35(1):259-65, 2011.

Donnelly, J. E.; Blair, S. N.; Jakicic, J. M.; Manore, M. M.; Rankin, J. W.; Smith, B. K. \& American College of Sports Medicine. American College of Sports Medicine Position Stand. Appropriate physical activity intervention strategies for weight loss and prevention of weight regain for adults. Med. Sci. Sports Exerc., 41(2):459-71, 2009.

Falsarella, G. R.; Gasparotto, L. P.; Barcelos, C. C.; Coimbra, I. B.; Moretto, M. C.; Pascoa, M. A.; Ferreira, T. C. \& Coimbra, A. M. Body composition as a frailty marker for the elderly community. Clin. Interv. Aging, 10:1661-6, 2015.

Friedenreich, C. M.; Woolcott, C. G.; McTiernan, A.; Terry, T; Brant, R.; Ballard-Barbash, R.; Irwin, M. L.; Jones, C. A.; Boyd, N. F.; Yaffe, M. $\mathrm{J}$. ; et al. Adiposity changes after a 1-year aerobic exercise intervention among postmenopausal women: a randomized controlled trial. Int. J. Obes. (Lond.), 35(3):427-35, 2011.

Frisoli, A. Jr.; Chaves, P. H.; Ingham, S. J. \& Fried, L. P. Severe osteopenia and osteoporosis, sarcopenia, and frailty status in community-dwelling older women: results from the Women's Health and Aging Study (WHAS) II. Bone, 48(4):952-7, 2011.

Howarth, N. C.; Huang, T. T.; Roberts, S. B.; Lin, B. H. \& McCrory, M. A. Eating patterns and dietary composition in relation to BMI in younger and older adults. Int. J. Obes. (Lond.), 31(4):675-84, 2007.

Huang, S. W.; Ku, J. W.; Lin, L. F.; Liao, C. D.; Chou, L. C. \& Liou, T. H. Body composition influenced by progressive elastic band resistance exercise of sarcopenic obesity elderly women: a pilot randomized controlled trial. Eur. J. Phys. Rehabil. Med., 53(4):556-63, 2017.

Janssen, I. \& Mark, A. E. Elevated body mass index and mortality risk in the elderly. Obes. Rev., 8(1):41-59, 2007.

Liao, C. D.; Tsauo, J. Y.; Huang, S. W.; Ku, J. W.; Hsiao, D. J. \& Liou, T. H. Effects of elastic band exercise on lean mass and physical capacity in older women with sarcopenic obesity: A randomized controlled trial. Sci. Rep., 8(1):2317, 2018.

Liu, C. J. \& Latham, N. K. Progressive resistance strength training for improving physical function in older adults. Cochrane Database Syst. Rev., 8(3):CD002759, 2009.

Lizana, P. A.; López, R. \& Albala, C. Effect of summer holidays on anthropometric measures and body composition of older adults, inadequacy of body mass index to detect changes during a critical period: a pilot study. Int. J. Morphol., 34(2):557-60, 2016.

Lloret Linares, C.; Ciangura, C.; Bouillot, J. L.; Coupaye, M.; Declèves, X.; Poitou, C.; Basdevant, A. \& Oppert, J. M. Validity of leg-to-leg bioelectrical impedance analysis to estimate body fat in obesity. Obes. Surg., 21(7):917-23, 2011.

Ministerio de Desarrollo Social. Ampliando la Mirada sobre la Pobreza y la Desigualdad. Metodologías, Diagnóstico y Desafíos para Chile y 
sus Territorios (2006-2015). Casen 2015. Encuesta de Caracterización Socioeconómica Nacional. Santiago de Chile, Subsecretaria de Evaluación Social, Ministerio de Desarrollo Social, Gobierno de Chile, 2016. http://observatorio.ministeriodesarrollosocial.gob.cl/casen$\mathrm{m} \mathrm{u} 1 \mathrm{t}$ i d i m e n s i o n a $1 / \mathrm{c}$ a s e n/d o c s / AMPUANDO_LA_MIRADA_SOBRE LA POBREZA_Y_LA_DESIGUALDADpdf

Ministerio de Salud. Documento Presentación Primeros Resultados Tercera Encuesta Nacional de Salud (ENS) 2016-2017. Santiago de Chile, Departamento de Epidemiología, Ministerio de Salud, Gobierno de Chile, 2018. Available form: https://www.minsal.cl/wp-content/uploads/ 2017/11/ENS-2016-17_PRIMEROS-RESULTADOS.pdf

Payab, M.; Hasani-Ranjbar, S.; Zahedi, H.; Qorbani, M.; Shateri, Z.; Larijani, B. \& Soroush, A. The effect of Norouz holiday on anthropometric measures and body composition. J. Diabetes Metab. Disord., 14:7, 2015.

Prince, M. J.; Wu, F.; Guo, Y.; Gutierrez Robledo, L. M.; O'Donnell, M.; Sullivan, R. \& Yusuf, S. The burden of disease in older people and implications for health policy and practice. Lancet, 385(9967):549-62, 2015.

Rogers, M. E.; Sherwood, H. S.; Rogers, N. L. \& Bohlken, R. M. Effects of dumbbell and elastic band training on physical function in older innercity African-American women. Women Health, 36(4):33-41, 2002.

Schulte, J. N. \& Yarasheski, K. E. Effects of resistance training on the rate of muscle protein synthesis in frail elderly people. Int. J. Sport Nutr. Exerc. Metab., 11 Suppl.:S111-8, 2001.

Spirduso, W. Physical Dimensions of Aging. Champaign (Il.), Human Kinetics, 1995.

Stevenson, J. L.; Krishnan, S.; Stoner, M. A.; Goktas, Z. \& Cooper, J. A. Effects of exercise during the holiday season on changes in body weight, body composition and blood pressure. Eur. J. Clin. Nutr., 67(9):944-9, 2013.

Strasser, B.; Keinrad, M.; Haber, P. \& Schobersberger, W. Efficacy of systematic endurance and resistance training on muscle strength and endurance performance in elderly adults--a randomized controlled trial. Wien. Klin. Wochenschr., 121(23-24):757-64, 2009.

Warburton, D. E.; Nicol, C. W. \& Bredin, S. S. Health benefits of physical activity: the evidence. CMAJ Can. Med. Assoc. J., 174(6):801-9, 2006.

Yanovski, J. A.; Yanovski, S. Z; Sovik, K. N.; Nguyen, T. T.; O'Neil, P. M. \& Sebring, N. G. A prospective study of holiday weight gain. N. Engl. J. Med., 342(12):861-7, 2000.

Yarasheski, K. E. Exercise, aging, and muscle protein metabolism. $J$. Gerontol. A Biol. Sci. Med. Sci., 58(10):M918-22, 2003.
Corresponding author:

Pablo Lizana Arce PhD.

Laboratory of Morphological Sciences

Instituto de Biología

Pontificia Universidad Católica de Valparaíso

Av. Universidad 330

Curauma, Placilla

Valparaíso

CHILE

Email: pablo.lizana@pucv.cl

Received: 24-02-2020

Accepted: 16-04-2020 